\title{
A AULA INAUGURAL DO CURSO DE GEOMETRIA APLICADA ÀS ARTES NO CONSERVATÓRIO IMPERIAL DE ARTES E OFÍCIOS \\ (Paris, Janeiro de 1865) ${ }^{1}$ \\ AIMÉ LAUSSEDAT

\author{
Tradução de \\ LAURENT POLIDORI ${ }^{1,2}$ \\ ANTONIO MARIA GARCIA TOMMASELLI ${ }^{2}$ \\ ${ }^{1}$ CNAM / ESGT \\ 1 Boulevard Pythagore, 72000 Le Mans -França \\ laurent.polidori@esgt.cnam.fr \\ Rua Roberto Simonsen, 305, 19060-900, Presidente Pudente, S.P. Brasil \\ tomaseli@fct.unesp.br
} \\ ${ }^{2}$ Universidade Estadual Paulista - UNESP, Departamento de Cartografia
}

\section{RESUMO}

Nesta comunicação, apresenta-se a tradução do texto integral da aula inaugural do Coronel Aimé Laussedat (1819-1907), professor suplente no Conservatoire Impérial des Arts et Métiers (antigo nome do CNAM), comentado pelo autor na versão original, publicado pela Associação Francesa de Topografia (revista XYZ vol. 133 $4^{\circ}$ trimestre 2012, pag. 57-64), traduzido por Laurent Polidori e Antonio M. G. Tommaselli.

\section{Senhores,}

Antes de abordar as questões que devem ser o objeto dos nossos estudos neste ano, deixem-me expressar minha gratidão ao erudito General, que dirige com tanta solicitude este lindo estabelecimento, aos ilustres professores e outros membros do

${ }^{1}$ OUVERTURE DU COURS DE GÉOMÉTRIE APPLIQUÉE AUX ARTS AU CONSERVATOIRE IMPÉRIAL DES ARTS ET MÉTIERS. (Título original).

Bol. Ciênc. Geod., sec. Comunicações/Trab. Técnicos, Curitiba, v. 19, nº 3, p.512-524, jul-set, 2013. 
Conselho de aperfeiçoamento do Conservatório, pelo testemunho de confiança com o qual me têm honrado.

Ocupo aqui o lugar de um homem cujo nome é justamente famoso, e que, de todas as dignidades das quais é investido, talvez prefira o título, alias tão respeitado, de professor no Conservatório de Artes e Ofícios.

Este título lembra, de fato, o Barão Charles Dupin, atualmente senador e membro sênior da Academia de Ciências, os brilhantes sucessos de sua juventude e os serviços que prestou à classe trabalhadora e industrial, da qual sempre se declarou amigo e conselheiro.

Ilustrada pelo Sr. Charles Dupin, esta cátedra foi consecutivamente ocupada por suplentes dignos de mérito. Foi ainda há pouco, ocupada pelo digno Sr. Tom Richard, que a morte precoce retirou de funções às quais estava afeiçoado.

Não tive a honra de conhecer pessoalmente o Sr. Tom Richard, mas a sorte ou minha boa fortuna me deram a oportunidade, por duas vezes, de apreciar suas raras qualidades como homem e como chefe de fábrica. Peço-vos permissão para relatar estes dois fatos, os quais por simples que sejam, serão provavelmente suficientes para mostrar quem era o Sr. Tom Richard na vida privada.

O primeiro aconteceu há mais de vinte anos. Todos os anos, os alunos da Escola de Aplicação de Metz viajam para visitar as principais plantas do Leste da França, para estudar experimentalmente o efeito das máquinas cuja teoria lhes fora explicada anteriormente. Em 1844, um dos meus colegas foi assim enviado para Framont, no Vosges. Voltou encantado dessa expedição, e o que lhe impressionara tanto, não era a ordem material que é normalmente encontrada nos grandes estabelecimentos desse país trabalhador, mas a notável atitude dos trabalhadores e o apego singular que manifestavam por seu diretor. O Diretor tão amado por seus subordinados era o Sr. Tom Richard.

Alguns anos mais tarde, devido à função de oficial Engenheiro do Exército, fui chamado ao vale de Aldudes, na fronteira extrema dos Pirinéus ocidentais. Encontrei no meu caminho, e visitei com grande interesse, as forjas de Banca, que dão um pouco de vida a esse país quase selvagem. Fiquei surpreso, por minha vez, pelo coro de louvor que se levantava tanto na fábrica quanto na aldeia, em torno do nome do engenheiro. Novamente era o Sr. Tom Richard.

Os serviços que o professor prestou aqui são recentes demais para que seja preciso lembrá-los. Aliás, não tive a intenção nem o tempo para escrever uma biografia, no entanto, pensei que seria natural invocar minhas lembranças para honrar a memória do homem de bem ao qual eu sucedi.

Tendo cumprido este dever, estou chegando ao tema que devo desenvolver diante dos senhores durante o trimestre do qual dispomos ${ }^{2}$.

\footnotetext{
${ }^{2}$ O programa do curso de geometria aplicada às artes, aprovados pelo Conselho de aperfeiçoamento, inclui os princípios da geometria elementar, da trigonometria e da geometria de curvas, as quadraturas e medições de volume, a topografia, e, particularmente, o estudo do terreno em termos de obras públicas, os conceitos de astronomia própria para orientar os fabricantes de instrumentos de precisão e,
}

Bol. Ciênc. Geod., sec. Comunicações/Trab. Técnicos Curitiba, v. 19, nº 3, p.512-524, jul-set, 2013. 
Dentre todas as aplicações da geometria, talvez não exista nenhuma que seja de uma utilidade tão geral como essa arte que, provavelmente por esse motivo recebeu o nome de geometria prática, mas que hoje é mais comumente e mais exatamente denominada de Topografia.

A palavra Topografia significa descrição de localidades. A Topografia tem efetivamente como objeto a representação detalhada do terreno, de todos os acidentes naturais que ocorrem na superfície, bem como das obras que os homens têm erigido em sua superfície.

Quando a descrição engloba uma grande extensão do território, todo um país, isso leva a remover gradualmente os detalhes e, finalmente, a reter apenas as características gerais do solo, tais como a localização dos centros populacionais, as montanhas, as direções dos rios, as costas e as principais feições lineares das grandes obras públicas. Vejam de imediato, senhores, o quão próximas são as relações que existem entre a Topografia e a Geografia, sendo, por isso, muito difícil traçar uma linha divisória entre elas. Considerada assim em toda a sua generalidade, a Topografia originou-se, como a Geografia, nos primeiros tempos da civilização. Encontramos seus fundamentos nos poetas mais antigos, nos historiadores mais antigos, que também foram os primeiros Geógrafos, na Bíblia e em autores profanos ${ }^{3}$.

Das duas principais formas de descrição, o discurso ou o desenho, o primeiro, que inicialmente foi o único a ser utilizado, será sempre o mais expressivo e eu poderia dizer que o mais atraente, pois se dirige à mais ativa das nossas faculdades, a imaginação, e a apanha sem recorrer aos nossos sentidos. Se os relatos de viagens têm o privilégio de cativar a atenção tanto da juventude como aqueles de meia idade, não seria devido tanto ao encanto das descrições como ao interesse dos episódios dramáticos? Eu poderia prová-lo se fosse preciso, com base no êxito das geografias modernas de Malte-Brun e da sua escola, cujo método descritivo tem uma superioridade tão óbvia sobre aquela que se utilizava anteriormente e que reduzia um dos ramos mais fecundas dos nossos conhecimentos à aridez de uma nomenclatura.

Finalmente, será que cada um de nós não sabe, por sua própria experiência, que mesmo em obras de pura imaginação, os autores mais apreciados são aqueles que, pela veracidade, ou deveria dizer, pela verossimilhança de suas pinturas, e não apenas pela magia da sua linguagem, sabem nos levar até o lugar da cena onde acontece a ação que é o sujeito de sua história.

Não se surpreendam senhores, se eu parei por alguns momentos nesse aspecto tão aparentemente distante do objeto que deve nos ocupar especificamente; mas os

finalmente, a geometria da máquina ou cinemática. Será discutido nesta palestra apenas a Topografia, que deve ser o tema das aulas do inverno de 1865.

3 Nos livros aos quais eu estou me referindo, não se acham apenas descrições topográficas e itinerários; muitas vezes se trata também de divisão de terras, o que envolve operações de agrimensura. 
historiadores e os poetas não são os únicos a usar a linguagem para descrever o país ou o local ao qual eles querem levar os seus leitores a conhecer. Desde o engenheiro, que concebe um grande projeto, até o simples agrimensor que delimita duas propriedades, todos aqueles que têm que estudar o terreno sentem a necessidade de juntar à melhor carta, ao melhor desenho, um relatório explicativo mais ou menos extenso. E isso nem sempre é a tarefa mais fácil, de dar a essas explicações toda a clareza desejável; mas a arte de bem observar e o talento para expor aos outros, somente pela linguagem, o que nós mesmos vimos, não se ensinam muito e só podem ser adquiridas por uma longa experiência.

Vou rapidamente abandonar essa ordem de considerações que não achei inútil dar-vos a vislumbrar, e estou chegando ao segundo meio de descrição, o desenho, que também é uma linguagem e, como muitas vezes e justamente foi observado, a única linguagem verdadeiramente universal.

O desenho pode ser imitativo ou convencional. No primeiro caso, podemos dizer que se explica por ele mesmo, mas é geralmente insuficiente, e veremos por quê. No segundo caso, é útil, é quase sempre indispensável, ter a chave das convenções adotadas. O desenho imitativo foi, naturalmente, o primeiro a ter sido utilizado. Assim, encontramos vistas em perspectiva, muitas vezes irregulares, de cidades inteiras ou grandes monumentos nas medalhas, nos vasos e nos baixosrelevos antigos, e mais tarde nos manuscritos da Idade Média e nas primeiras tábuas gravadas.

A maioria destes desenhos e das cartas, inicialmente muito imperfeitos, sobre as quais foram inseridos, podem ser relacionados com o sistema chamado de perspectiva cavaleira, um sistema que continuou até o século passado.

O único progresso significativo que descobrimos, a partir do Renascimento, consiste na observação cada vez mais exata das regras da perspectiva linear e, para citar um só exemplo, os desenhos admiráveis dos cercos de Breda, de La Rochelle e da Ilha de Ré executados por Callot na primeira metade do século XVII, pertencem à Topografia pitoresca e podem ser considerados como obras-primas do gênero. Mas deve-se notar de imediato que este aperfeiçoamento, consequência imediata daquele das artes imitativas em geral, era aplicável apenas para a descrição de uma área muito limitada de terra, como a de uma cidade, de uma fortaleza ou de um porto. Reunidas com as plantas propriamente ditas, que sabíamos levantar geometricamente, por muito tempo, as vistas, que sozinhas não forneciam nenhuma medida, ofereciam grande interesse; mas quando se tratasse de um território relativamente extenso e em especial se se tratasse de Topografia geral, tornava-se impossível usar este método. Portanto, a construção de cartas de províncias ou estados permaneceu deficiente até que se entendesse que era baseada quase que exclusivamente em operações geométricas cuja dificuldade aumentava, na verdade, com a extensão que se tinha de abranger.

Eu não poderia, senhores, sem gastar muito mais tempo do que eu tenho, vos apresentar a história da Topografia moderna e dos métodos cada vez mais perfeitos que se tem utilizado. Portanto, apenas tentarei vos indicar os pontos principais.

Bol. Ciênc. Geod., sec. Comunicações/Trab. Técnicos Curitiba, v. 19, nº 3, p.512-524, jul-set, 2013. 
As primeiras tentativas de levantar cartas detalhadas abrangendo um país inteiro foram inspiradas pelo mais nobre de todos os sentimentos, o amor à independência. A Suécia, apenas libertada do jugo dos dinamarqueses, a Polónia já sendo ameaçada, a Holanda envolvida na luta heroica que a livraria da dominação estrangeira, foram as primeiras nações que, no início do século XVII, entenderam a necessidade de estudar, passo a passo, os recursos que a configuração do terreno pode oferecer para a sua defesa ${ }^{4}$.

Logo foram imitadas pela Alemanha, a Suíça, a Inglaterra, alguns dos estados da Itália e particularmente o Piemonte e a Sabóia, os quais, graças à ajuda dos príncipes esclarecidos e artistas qualificados, logo tiveram as mais belas cartas da época.

Na França, algumas províncias que já tinham um cadastro e registros fundiários também fizeram realizar cartas topográficas, mas é preciso chegar até meados do século XVIII, até a época dos Cassini, para achar um grande trabalho global, que por sua vez deveria servir como um modelo para todos os empreendimentos do mesmo tipo.

Durante o reinado de Luis XIV, foram levantadas plantas das cidades, especialmente aquelas fortificadas. Vauban e engenheiros sob seu comando davam grande atenção a este trabalho. Por outro lado, os engenheiros geógrafos, passaram a ser, a partir de então, responsáveis por levantar a carta dos países percorridos por nossas forças armadas, e saíram, mais tarde, dessa instituição, homens de rara habilidade, observadores distintos e sábios geômetras. No entanto, deve-se dizer, os trabalhos dos engenheiros da época de Luís XIV não parecem ter contribuído para o progresso da arte. Estaria reservada para os reinados de Luís XV e Luís XVI a elevação da Topografia francesa para a vanguarda em todos os gêneros.

Luis XV, deve-se reconhecer, teve um gosto particular pela Geografia, bem como para observações astronômicas, mas sabemos que ele não tinha menos gosto para os prazeres, e esse conjunto de inclinações tão opostas deu à luz a uma obra, ou melhor, uma obra-prima que reflete as duas juntas. Quero falar dessa linda carta de caças, ainda hoje um dos mais lindos exemplares da Topografia, que inclui Versailles e seus arredores, num raio de 14 léguas.

Direi aqui só uma palavra sobre a carta de Cassini, cujo empreendimento remonta a 1730 . Teremos a oportunidade de voltar em uma das aulas posteriores, e limito-me a lembrar que esta grande operação foi uma das primeiras, talvez a primeira, se excetuarmos um teste realizado na Holanda, a usar para o levantamento, observações astronômicas e grandes triangulações, que anteriormente eram reservadas para o estudo da figura da terra.

Gostaria de acrescentar que, com a situação financeira deplorável, que não permitia que Luis XV realizasse esta grande obra à custa do tesouro, o príncipe teve de contentar-se em executá-la sob o seu patrocínio. Assim, é à ilustre família

${ }^{4}$ Mémorial du dépôt de la guerre, volume I. Relatório do Capitão Soulavie, engenheiro geógrafo, sobre o estado da Topografia na Europa, publicado em 1802.

Bol. Ciênc. Geod., sec. Comunicações/Trab. Tecnicos Curitiba, v. 19, nº 3, p.512-524, jul-set, 2013. 
Cassini ${ }^{5}$ que cabe toda a glória de tê-la realizado e concluído. Grande e nobre exemplo, talvez pouco conhecido e que prova tão justamente o que podem a iniciativa individual e a perseverança postas ao serviço de uma ideia justa!

Luis XVI havia herdado a paixão de seu avô pela Geografia, e ninguém ignora os esforços louváveis que fez para o aperfeiçoamento das artes que se relacionam com a Marinha. Viagens de descoberta, trabalhos hidrográficos significativos foram realizados por suas ordens e deram à França a superioridade que a Espanha tinha até então mantido na arte de reconhecer as costas.

É impressionante, por exemplo, que as cartas do mar Báltico, levantadas no final do século passado pelo nosso colega Fleurieu, ainda fossem os melhores documentos que se possuísse para navegar neste mar, quando eclodiu, em 1854, a guerra com a Rússia.

Foi no reinado de Luís XVI e nos primeiros anos da revolução que aconteceram também os trabalhos do ilustre Beautemps-Beaupré, que supervisou o reconhecimento de nossas costas e treinou tantos hábeis engenheiros hidrógrafos que perpetuam as suas tradições.

Enquanto a Hidrografia e a Topografia geral realizavam notáveis progressos, dos quais mal pude vos dar uma ideia, a Topografia local não ficou atrasada. A escola de Mézières, que teve a honra de ter Monge entre seus professores e deu à França eminentes engenheiros militares, foi a primeira a vislumbrar os imensos benefícios de um método originalmente proposto pelo geógrafo Buache para representar as irregularidades do fundo do mar, e depois aplicado por Ducarla, de Genebra, à expressão do relevo do terreno, tendo-o incorporado ao ensino.

Permitam-me, senhores, parar por alguns instantes em um assunto do qual eu falarei muito durante essas aulas e sobre o qual preciso chamar vossa atenção.

As cartas e plantas topográficas construídas geometricamente dão à primeira vista, ou quando se quiser mais precisão, usando uma escala, as distâncias horizontais entre os diferentes pontos do terreno. Mas como será que as diferenças de níveis entre estes pontos são neles indicadas, como podemos saber se estamos em um país de planícies, de colinas ou de montanhas, se entre dois considerados pontos um é mais ou menos alto do que o outro e de quanto? Todas estas questões certamente valem a pena serem consideradas.

Nas cartas antigas as vilas, as aldeias e até a vegetação eram representadas em perspectiva cavaleira, o que conduziria, estendendo-se aquele princípio a uma espécie de representação pitoresca dos acidentes do solo, a qual, nas cartas em escala pequena, ou como se diz em pequenos pontos, degenerou numa série de acentos circunflexos encaixados uns nos outros. Este símbolo, que conforme a expressão de Lacroix, equivale a estas palavras: "aqui há montanhas", todos vocês o conhecem, porque diariamente vemos cartas semelhantes nas prateleiras dos cais do Sena.

\footnotetext{
${ }^{5}$ Cassini de Thury (ou Cassini III) e Cassini IV, porque a ciência sendo hereditária na família, vieram a denominar seus membros como se fossem príncipes, por uma série cronológica.
}

Bol. Ciênc. Geod., sec. Comunicações/Trab. Técnicos Curitiba, v. 19, nº 3, p.512-524, jul-set, 2013. 
Evidentemente, uma forma de desenho semelhante só poderia ser muito imperfeita, mesmo nas cartas em grandes pontos, e até mesmo as plantas detalhadas; portanto, apesar de seus defeitos terem sido consideravelmente atenuados pelo uso sistemático de hachuras dirigidas aproximadamente no sentido do maior declive do terreno $^{6}$, havia uma enorme lacuna, um obstáculo dos mais graves ao progresso da Topografia.

É esta lacuna que o método de Buache, generalizado por Ducarla, tem permitido superar da maneira mais satisfatória. É justo dizer que a ideia engenhosa de Buache (1737) aparece, pelo menos de forma embrionária, nas cartas hidrográficas do holandês Cruquius (1729).

Embora já se tivesse pensado em incluir nas plantas ao lado de cada ponto notável, um número que expressasse a distância deste ponto a um plano horizontal de referência superior ou inferior ao terreno, estes números não poderiam ser multiplicados sem confusão e seria com grande dificuldade que se conseguiria, ao lê-los, ter uma ideia ainda incompleta do relevo.

A notação de Buache fez cessar esta confusão. Com efeito, imaginem que os pontos de uma carta marcados com uma mesma cota de altitude unidos por uma curva contínua, só precisarão de um número ou, no máximo, alguns números escritos, de longe em longe, ao lado dessa curva, para conhecer, não mais pontos isolados do terreno, mas toda a série de pontos situados no mesmo nível.

Estas mesmas curvas poderão ser mais ou menos numerosas, mas elas não produzirão nenhuma confusão, porque elas são distintas uma da outra e nunca se interceptam. Além disso, elas têm a vantagem inestimável de permitirem perceber, de relance, através de suas formas, as inflexões do terreno, e pela sua proximidade ou afastamento, os declives mais ou menos íngremes, mais ou menos suaves.

Pode-se te uma ideia clara deste método tanto simples quanto geométrico de representar o relevo, considerando as curvas de nível como as projeções, na carta, dos limites sucessivos de um mar que teria inundado o país inteiro e depois recuado gradualmente, baixando periodicamente em quantidades iguais.

Desde que a escola de Mézières teve o mérito de introduzi-la no serviço da engenharia militar, a notação das curvas de nível passou à maioria dos outros serviços públicos. Os países estrangeiros a adotaram e podemos dizer que, agora, sua utilização é geral ${ }^{7}$.

\footnotetext{
${ }^{6}$ Não se deve presumir que a idéia de linhas de maior declive foi posterior à das curvas de nível, das quais parecem hoje ser uma conseqüência natural. Podemos garantir o contrário, olhando o livro II dos Elementos de Topografia militar, de Hayne, engenheiro a serviço da Prússia, livro oitavo, traduzido do alemão, Paris, 1806, onde o uso das hachuras seguindo as linhas de maior declive é ensinado sem qualquer referência às curvas de nível que o autor não pareceter conhecido.

${ }^{7}$ Acredito que as obras de drenagem têm contribuído muito para destacar as vantagens das curvas de nível. Na Inglaterra, os conselhos de salubridade de várias grandes cidades fizeram incluir estas curvas sobre as plantas para estudar com mais facilidade as possibilidades de escoamento das águas, o traçado dos esgotos, etc. Eu mesmo vi um exemplo em Portsmouth em 1851. O Sr Delesse, engenheiro-chefe de minas, por sua vez, fez uma aplicação muito útil, por meio de curvas de cores diferentes para
}

Bol. Ciênc. Geod., sec. Comunicações/Trab. Tecnicos Curitiba, v. 19, nº 3, p.512-524, jul-set, 2013. 
Nas cartas gravadas ou manuscritas, nas quais se quer acentuar o relevo de uma forma mais evidente, nas cartas de pequena escala que ficariam sem efeito se fossem usadas somente curvas, as hachuras e os tons que se usam para produzir estes efeitos têm eles mesmos estas linhas como diretrizes. É assim que foram gravadas as belas folhas da carta da França, cujas curvas foram desenhadas no campo pelos oficiais do corpo do Estado maior. É da mesma maneira que os oficiais do exército e os estudantes de nossas escolas especiais procedem para o desenho das cartas chamadas "à l'effet”.

Espero, senhores, poder dar-vos na continuação, detalhes mais completos sobre os serviços que o uso de curvas de nível já permitiram e aqueles para os quais ele é requisitado, tanto no estudo como na execução de projetos de qualquer tipo, com o objetivo final de qualquer modificação da superfície do solo ${ }^{8}$.

Antes de concluir este histórico, acrescentarei algumas palavras sobre os instrumentos.

Os antigos mediam os campos, traçavam estradas, construíam aquedutos. Os Romanos, por exemplo, tinham agrimensores, cujas funções deviam ser de grande importância nesse povo essencialmente agricultor. Eles tinham hábeis engenheiros, não podemos duvidar, e uns e outros precisavam de instrumentos adequados para a sua arte. Mas a verdade é que sabemos muito pouco sobre isso, e vou abster-me de falar para não me expor a fazer falsas conjecturas.

Os autores italianos do século XVI que parecem ter sido os primeiros a escrever sobre geometria prática, falam de instrumentos semelhantes aos que foram usados desde então. É ainda bastante notável encontrar a bússola usada desde 1538 para levantar plantas ${ }^{9}$.

A construção dos instrumentos de Topografia naturalmente beneficiou-se dos progressos das artes mecânicas, e seguiu as mesmas fases que as dos instrumentos de astronomia prática. Com efeito, quase todas as partes destes instrumentos são idênticas nos seus princípios: círculos divididos, verniers, lunetas, níveis; até a utilização destes dois tipos de aparelhos, na verdade, só difere pelo grau de precisão que se quer alcançar, e é nesse grau de precisão que se apoia o fabricante.

Esta última observação me leva a antecipar algumas objeções e respondê-las. Será que estou me deixando levar pelas minhas preocupações habituais, que os métodos que penso em introduzir neste curso são um pouco especiais, fora dos

representar as superfícies que separam as diferentes camadas geológicas do solo sobre o qual se construiu a cidade de Paris.

${ }^{8}$ Mencionarei aqui para meus leitores, como para meu público, as belas cartas em relevo do Sr L.J. Bardin, ex-chefe dos trabalhos gráficos da Ecole Polytechnique, e o livro que ele publicou sob o título: A Topografia ministrada por cartas em relevo e desenhos, com texto explicativo.

${ }^{9}$ Quesiti e Inventioni diversificada Nicolo Tartaglia, di nuovo restampati, libro quinto. Desde que esse discurso foi escrito, o Conservatório de Artes e Ofícios adquiriu um instrumento projetado tanto para a medição de ângulos verticais como de ângulos horizontais, e que levava uma pequena agulha magnética, obviamente destinada a dar a orientação das direcções indicadas por uma das alidades. O instrumento é datado de 1559 e assinado por Aegidius Quiniet, Antverpianus (de Antuérpia). A declinação, que era oriental naquela época, é indicada no limbo percorrido pela agulha.

Bol. Ciênc. Geod., sec. Comunicações/Trab. Técnicos Curitiba, v. 19, nº 3, p.512-524, jul-set, 2013. 
hábitos comuns e das necessidades mais frequentes, será que são principalmente adequados para aplicações militares, ou no máximo para alguns serviços públicos?

Não hesito em afastar todos esses medos e digo, pelo contrário, que é de interesse geral avançar para esse objetivo comum, a descrição cada vez mais exata de todas as partes do território da França.

Aqui também espero ser interrompido.

Mas será que não temos o cadastro e a carta do estado maior? Para que precisamos de outra coisa, exceto os inevitáveis estudos para o estabelecimento de um projeto ou para a consideração de um assunto especial que requer uma planta detalhada, das numerosas cotas de nivelamento?

Tentarei explicar claramente meu pensamento sobre cada um dos temas sensíveis que acabei de levantar.

E primeiramente, estou tão longe de ignorar a importância capital dos documentos existentes, que me ouvirão dizer e repetir que se deveria fazer uso mais frequente deles.

Meu objetivo é até de vos indicar com cuidado todos os recursos que eles oferecem para os operadores.

Assim, a carta da França tem como fundamento a magnífica triangulação iniciada por Delambre e Méchain, concluída com rara perfeição por engenheiros geógrafos do Arquivo do Exército. É sobre os vértices dessa triangulação que eu recomendaria amarrar todas as operações de qualquer importância, estejam elas relacionadas com o interesse público ou privado.

Eu imediatamente relacionarei com esses valiosos dados aqueles resultantes do nivelamento da rede de linhas ferroviárias e dos grandes rios, encomendados pelo $\mathrm{Sr}$ Ministro de Obras Públicas e executado com uma admirável precisão pelo Sr. Bourdaloue $^{10}$. Nada mais fácil, graças às indicações fornecidas pelo livro do $\mathrm{Sr}$ Bourdaloue $^{11}$, do que encontrar em cada uma das localidades percorridas pelos seus funcionários, os marcos de ferro fundido indicando de maneira aparente a sua cota de altitude acima do nível médio do mar.

Também eu aconselharei usar esses marcos todas as vezes que se puder, e registrar os nivelamentos deles, qualquer que seja o assunto.

Seria altamente desejável que se compelisse, nos serviços públicos, nas grandes administrações e até nas empresas particulares, a coletar, coordenar todos os resultados das operações realizadas com cuidado, para fazê-los contribuir a esse objetivo que já mencionei, uma descrição cada vez mais detalhada do território. Quantas vezes o mesmo terreno foi explorado, medido por engenheiros e

${ }^{10}$ Esta precisão é tão boa, de acordo com o Sr. Bourdaloue, que por quilômetro não há discrepância superior a $1 \mathrm{~mm}$, e que de uma extremidade da França até a outra a discrepância atinge apenas 3 centímetros. Quanto ao Engenheiro-chefe Breton (de Champ), encarregado do serviço de controle desta bela operação, diz que esta avaliação não é nada exagerada.

${ }^{11}$ Nivelamento geral da França (linhas de base e diversas anotações) por Paul-Adrien Bourdaloue, 2 vols, oitavo, Bourges, 1864.

Bol. Ciênc. Geod., sec. Comunicações/Trab. Tecnicos Curitiba, v. 19, no 3, p.512-524, jul-set, 2013. 
agrimensores, porque não se tinha conservado os arquivos das primeiras operações, ou porque tinham sido encaixotados ${ }^{12}$.

Voltemos para a carta da França e as plantas cadastrais. A carta da França é composta de $258^{13}$ folhas gravadas "à l'effet", na escala de 1:80.000 com cotas de altitudes espalhadas regularmente. Ela atende perfeitamente ao objetivo a que se tinha proposto, e não há nenhuma razão para se surpreender quando se pensa no trabalho que exigiu de duas gerações de oficiais cientistas ${ }^{14}$. Do ponto de vista militar, esta carta não deixa nada a desejar, mas não seria razoável pedir o que sua escala limitada não permite fornecer e, por isso, essa carta nunca foi considerada própria ao estudo de grandes projetos de obras públicas.

No entanto, os rascunhos que o Arquivo do Exército pôs ansiosamente à disposição dos engenheiros têm prestado grandes serviços, especialmente nos préprojetos de traçado de ferrovias. Esses rascunhos são desenhados na escala de 1:40.000 e cobertos por curvas de nível. São essas curvas que têm sido tão úteis ${ }^{15}$, e é óbvio que numa escala maior, teria sido possível melhorar adiante os estudos preliminares. Mas em termos de despesas, a adoção de uma escala maior que 1:40.000 para o rascunho, e que 80.000 para a carta gravada podia ter encontrado obstáculos insuperáveis na época em que foi decretado este grande empreendimento, e só se pode ficar satisfeito, em todos os aspectos, com a solução que foi escolhida. Por isso, não sou menos inclinado a acreditar que as cartas em escalas grandes em breve tornar-se-ão indispensáveis, e os nossos vizinhos britânicos parecem bem convencidos disso, pois após a execução da carta da Inglaterra na escala 1:63.400 (1 polegada por 1 milha), não hesitaram em empreender e concluir a carta da Irlanda na escala 1:10.600 (6 polegadas por 1 milha ${ }^{16}$ ). Só esta última compreende 1.907 folhas cobertas por muitas curvas de nível, várias das quais em cada folha foram levantadas com escrupulosa exatidão, e usadas para desenhar as curvas intermediárias.

${ }^{12}$ Circular do Sr Ministro de Agricultura, Comércio e Obras Públicas, em 16 de agosto de 1858, sobre a conveniência de um nivelamento geral da França.

13 Não incluindo Savoie e o condado de Nice.

14 Nada melhor, para se ter uma idéia exata das dificuldades e da perfeição deste trabalho, do que se referir ao relatório publicado pelo Coronel (hoje General) Blondel, diretor do Arquivo da Guerra. Paris, 1853.

15 O Sr Bourdaloue publicou à expensas próprias a carta do departamento do Cher na escala de 1:40.000 Ele também tinha proposto publicar o nivelamento geral da França, relacionando-o com as minutas da carta do exército. A administração era a favor desse projeto, e o Sr Ministro das obras públicas havia consultado os vereadores para pedir a sua ajuda. Ao que parece estes vereadores não estavam conscientes, pelo menos em sua maioria, da utilidade da despesa para a qual foramconvidados a votar. Talvez estivessem mais dispostos, mais tarde, a participar de um trabalho muito mais considerável, a publicação das cartas cadastrais numa escala de 1:10.000 com curvas de nível.

${ }^{16}$ Na Bélgica, o Sr P.C. Popp, ex-controlador do cadastro, publica, com a aprovação do governo, o Atlas de parcelas cadastrais de todos os municípios na escala 1:2.500 ou 1:5.000. A planta de cada município é acompanhada por uma tabela indicadora detalhada, e da carta cadastral original com todas as mudanças. O preço médio da carta de um município é de 20 Fr. Nada seria mais útil de que imitar este exemplo na França.

Bol. Ciênc. Geod., sec. Comunicações/Trab. Técnicos Curitiba, v. 19, nº 3, p.512-524, jul-set, 2013. 
Não será a prova, podemos dizer palpável, dessa necessidade incessante de progresso que estimula as nações bem como os indivíduos? E, de fato, à medida que as ciências e as artes se desenvolvem, o solo, todos nós sabemos, a cada dia adquire um maior valor. Portanto, não se torna necessário examinar com cada vez mais cuidado os seus recursos, cujos principais elementos nos são fornecidos pela topografia?

Veremos agora o que são as plantas cadastrais, dos quais gosto de reconhecer a excelente execução naqueles nossos departamentos onde tive a oportunidade de consultá-los. Estas plantas são traçadas nas maiores escalas e, consequentemente, contêm todos os detalhes que se poderia querer em termos de planimetria, mas não dão nenhuma ideia exata do relevo, não mostram nenhuma indicação de nivelamento ${ }^{17}$. Podemos dizer sem hesitação que elas estão incompletas, se tomarmos o ponto de vista da exploração agrícola racional, que requer toda a ajuda da arte; mas há mais, elas são insuficientes até considerando-os com suas características específicas. Se os Srs quiserem ter certeza, perguntem, eu não digo aos agrimensores, cuja opinião poderia ser suspeita, mas aos proprietários, aos cobradores de contribuições, aos juízes ${ }^{18}$, a todos aqueles, enfim, que estão envolvidos a qualquer título que seja na administração da propriedade fundiária.

Com efeito, qual era a dupla finalidade do cadastro? Uma distribuição equitativa (para a equalização) do imposto territorial e a criação de um título de propriedade oferecendo uma garantia legal ${ }^{19}$.

Entre estes dois objetivos, o primeiro foi conseguido de forma imperfeita, o segundo não o foi totalmente. Será que isso significa que é impossível? Certamente que não. Só seria necessária para alcançá-lo, a realização de operações que talvez não pudessem ser empreendidas de uma vez; deveria ser criado um serviço inteiro de conservação que geraria uma despesa considerável, é verdade, mas que evitaria mais tarde muitos erros de apreciação, muitos erros intencionais ou não intencionais sobre os conteúdos declarados pelo vendedor ao comprador, muitos processos ruinosos $^{20}$.

Assim, não há dúvida de que mais tarde ou mais cedo, a atualização do cadastro tornar-se-á indispensável, sendo então que se cumprirá completamente o desejo que expressei, não sendo o momento para insistir.

\footnotetext{
${ }^{17}$ Me garantiram que, há algum tempo, o uso de curvas de nível foi adotado por vários agrimensores. Eu não tenho muita informação sobre o assunto, mas realmente acredito que a multiplicação das obras de drenagem deve ter gerado e necessariamente gerará resultado. A administração florestal, por sua vez, prescreve oficialmente o uso de curvas de nível aos seus agentes, que executam autênticas plantas cadastrais (Diretrizes para os levantamentos topográficos e o desenho das cartas, Paris, 1860).

${ }^{18}$ Ver sobre o assunto o excelente livro intitulado Cadastro e delimitação de herança, por F.H.V. Noizet ex-magistrado. Paris, 1861, com um apêndice, Paris, 1863.

${ }^{19}$ Coleção sistemática de leis, decretos, regulamentos, etc., sobre o cadastro da França, aprovado pelo Ministro das Finanças, Paris, 1811. Título I, art. 14, Título IV, art. 167, Título VII, art. 703, e Título XV, art. De 1134-1144.

${ }^{20}$ Coleção metódica.
}

Bol. Ciênc. Geod., sec. Comunicações/Trab. Tecnicos Curitiba, v. 19, nº 3, p.512-524, jul-set, 2013. 
Resumo em algumas palavras as considerações que acabo de vos expor. O principal objetivo que me proponho nestas aulas é fazer com que os Srs. sejam capazes de usar os documentos existentes, indicando sua origem, o grau de exatidão, e finalmente o uso que deles pode ser feito nas operações de detalhe e até mesmo para o conhecimento cada vez mais perfeito da topografia da França. Também me esforçarei para deixar-vos conhecer os métodos e instrumentos que proporcionam a maior precisão e tendem a se aperfeiçoar cada dia, porque as operações a que se destinam só podem suceder-se com esta condição.

Se precisarem de provas dessa necessidade de precisão, as encontrei sem esforço no traçado das mil ramificações de nossas ferrovias e de nossos canais, mas escolherei dois exemplos ainda mais impressionantes, o Canal de Suez e o túnel dos Alpes. A perfuração do istmo de Suez é um empreendimento que teve um impacto tão grande, que pode ser lugar comum falar. Então falarei poucas palavras, mas confesso que tenho um verdadeiro prazer em citar novamente o nome do Sr. Bourdaloue, este operador modesto e hábil, a quem devemos o conhecimento de forma positiva, ao contrário do dito pelos engenheiros cientistas da expedição ao Egito, que o Mar Vermelho e o Mar Mediterrâneo têm o mesmo nível.

Foi somente graças a esta certeza, que se tornou possível tentar esta grande operação cujo provável resultado foi objeto de tanta controvérsia apaixonada. Se der certo, e tudo leva à esta esperança, a quem se deverá ? Ao Sr. Bourdaloue, sem dúvida, e a Linant Bey (Sr. Linant de Bellefonds), que orientou os estudos iniciais do canal $^{21}$, mas seria injusto omitir essas duas características importantes, ou seja, que esses engenheiros operavam em circunstâncias muito diferentes daquelas que tinham encontrado os seus antecessores, e eles tinham instrumentos muito mais perfeitos do que aqueles que se tinha 60 anos atrás. detalhes.

Chego agora ao túnel nos Alpes, do qual acho que devo dar um pouco mais de

Neste caso, de fato, não se tratou só de investigar a diferença de nível entre as duas extremidades da passagem, era ainda necessário desenhar o eixo do subterrâneo de modo a que as galerias abertas em ambas as extremidades viessem a concordar no mesmo ponto. Essa operação tem exigido os instrumentos mais delicados, usados nas circunstâncias mais difíceis ${ }^{22}$. Extraio a seguinte passagem de um documento inédito que me foi comunicado graças à bondade de um amigo que visitou recentemente essa grande obra ${ }^{23}$.

\footnotetext{
${ }^{21}$ Também, obviamente, à perseverança do Sr de Lesseps e ao talento de nossos engenheiros, o chefe dos quais é o meu velho amigo e camarada, Voisin.

${ }^{22}$ Ver sobre este assunto, e para todos os detalhes técnicos, as Palestras sobre o túnel nos Alpes, feitas na Escola Imperial de Engenharia Civil, pelo Sr. Conte, engenheiro-chefe da Savoie, folheto folio, litografada, 1864.

${ }^{23}$ Este aviso foi publicado há pouco no Correspondant.
}

Bol. Ciênc. Geod., sec. Comunicações/Trab. Técnicos Curitiba, v. 19, nº 3, p.512-524, jul-set, 2013. 
"Da entrada de Fourneaux ${ }^{24}$ tendo sido usada como ponto de partida, se levantou uma linha na direção da Bardonnèche, e depois de várias tentativas, se conseguiu atingi-la, mas era apenas uma operação preliminar, que não tinha precisão suficiente. Um marco fixo de alvenaria foi instalado a 2.949 metros de altitude, no ponto onde a linha traçada cortava a montanha; a esse ponto foi transportado um teodolito fornecido com uma excelente luneta astronômica, e desse pico na descendente colocaram-se marcos fixos até o fundo dos vales e até as vertentes opostas, onde observatórios foram estabelecidos no prolongamento exato do subterrâneo. Nestes observatórios foram fixadas, de forma invariável, lunetas dirigidas alternadamente para os marcos da parte superior e para um sinal de fogo no túnel. Assim se verifica, a cada dois ou três meses, a progressão do trabalho para garantir que não haja nenhum desvio lateral. É interessante investigar o grau de exatidão que comportam as observações e os instrumentos utilizados.

O teodolito transportado até o cume dos Alpes permitia medir ângulos com uma exatidão de cinco segundos; se esse erro máximo fosse cometido, o eixo formaria uma linha quebrada no meio do seu comprimento, dando a uma das extremidades um desvio de 29 centímetros. Essa pelo menos é a avaliação dos engenheiros responsáveis por esta importante operação.

Um erro de 20 centímetros também poderia ter sido cometido no estabelecimento de cada um dos observatórios. Afinal, pode presumir-se que ambos os ataques da obra se encontrem no centro da montanha com um erro de 40 a 50 centímetros, no máximo.

O comprimento do túnel, deduzido de duas séries distintas de triângulos cujos ângulos foram medidos com o maior cuidado, é 12.220 metros." (tradução nossa).

Finalmente o nivelamento, ainda mais difícil de executar, definiu a entrada do lado francês à altitude de 1.203 metros acima do nível do mar, e a saída do lado piemontês a 1.335 metros, o que dá uma diferença de 132 metros em que também pode haver um pequeno erro.

Estes dois exemplos são suficientes, com certeza, para provar a necessidade de uma busca de precisão cada vez maior. Felizmente, esta precisão é gradualmente introduzida nos hábitos, e longe de gerar perdas de tempo, ela ajuda, como terei ocasião de mostrar, a acelerar as operações, na maioria das circunstâncias.

Tentei, e ainda estou procurando, senhores, ir ao encontro de todas as objeções. Assim, poderiam me dizer que não se perfura diariamente o Mont Cenis ${ }^{25}$ ou o istmo de Suez, e que são obras que não existirão novamente; e que, portanto,

\footnotetext{
${ }^{24}$ Fourneaux e Bardonnèche são os nomes das duas aldeias mais próximas a cada extremidade do túnel, uma na França e outra na Itália.

25 Obedeço aqui à tradição, mas vale lembrar que o famoso túnel está a $25 \mathrm{~km}$ do Monte Cenis, no lado norte, e que na realidade ele passa abaixo do Monte Fréjus. O Sr Conte, em suas palestras, o denominou como o túnel nos Alpes, que é o nome que os italianos lhe deram (Traforo delle Alpe).
}

Bol. Ciênc. Geod., sec. Comunicações/Trab. Tecnicos Curitiba, v. 19, nº 3, p.512-524, jul-set, 2013. 
seria inútil escolher casos tão extraordinários, e finalmente, que eu talvez tenha uma tendência a dar ao meu ensino um caráter diferente do que deveria ter.

Apresso-me a tranquilizar àqueles que poderiam ter semelhante medo, comprometendo-me a usar somente demonstrações muito elementares na sua forma, mas sem perder de vista o objetivo que todos, engenheiros, artistas, operadores, temos que nos esforçar para atingir o aperfeiçoamento dos instrumentos e dos métodos.

Quanto às grandes obras realizadas ou sendo realizadas e que poderíamos ser tentados a considerar como o esforço supremo do homem lutando contra a natureza, queiram permitir que eu não acredite e que concorde com a visão bem diferente de uma das mentes mais brilhantes deste século.

"Em todas as épocas, diz Humboldt ${ }^{26}$, existem mentes fracas dispostas a acreditar com complacência que a humanidade alcançou o auge de seu desenvolvimento intelectual. Esquecem-se que pelo efeito da ligação íntima que une todos os fenômenos da natureza, o campo se expande à medida que avançamos, e que o limite que faz fronteira com o horizonte recua constantemente à frente do observador." (tradução nossa).

Tentemos, senhores, sem cairmos em qualquer tipo de exagero, penetrarmos no significado dessas grandes verdades, para as quais cada dia se faz uma brilhante confirmação.

Nas primeiras aulas que se seguem, exporei o conjunto de operações que são usadas para garantir a exatidão de um levantamento topográfico de qualquer extensão. Descreverei, nesta ocasião, as partes dos instrumentos de precisão, os princípios da construção e a utilização desses instrumentos.

Depois tratarei das operações de detalhe, apresentando os principais métodos utilizados nos diversos serviços públicos.

Insistirei particularmente nos procedimentos de nivelamento, nas propriedades das curvas de nível e nas numerosas e úteis aplicações que se podem fazer delas.

Finalmente, darei uma ideia geral de métodos expeditos de levantamento e de nivelamento que têm menos precisão do que os anteriores, mas, porém, que podem ser de grande utilidade em uma variedade de circunstâncias, principalmente em expedições remotas ou excursões rápidas através de países cuja topografia é pouco conhecida, em estudos de pré-projetos, etc.

Só peço aos meus alunos, em toda essa parte do curso, noções elementares de geometria e de trigonometria, noções que eu lembrarei se for preciso. Adiarei para as últimas aulas, e se eu tiver o tempo necessário, os detalhes relativos aos cálculos logarítmicos.

(Recebido em julho de 2013).

${ }^{26}$ Cosmos, Volume II, página 358 da edição francesa. Tradução do Sr Galusky.

Bol. Ciênc. Geod., sec. Comunicações/Trab. Técnicos Curitiba, v. 19, nº 3, p.512-524, jul-set, 2013. 